\title{
Role of Lean and Agile Supply Chain Models for Pellet Fuel Technologies
}

\author{
J. SZENDREI, B. KocSI, I. BudAI, G. GRASSELLI, E. SzŰCS \\ University of Debrecen, Faculty of Engineering, Department of Engineering Management and Enterprises, \\ szendrei.janos@eng.unideb.hu \\ University of Debrecen, Faculty of Engineering, Department of Engineering Management and Enterprises, \\ kocsi.balazs@inf.unideb.hu \\ University of Debrecen, Faculty of Engineering, Department of Engineering Management and Enterprises, \\ budai.istvan@eng.unideb.hu \\ University of Debrecen, Faculty of Engineering, Department of Engineering Management and Enterprises, \\ grasselli@eng.unideb.hu \\ University of Debrecen, Faculty of Engineering, Department of Engineering Management and Enterprises, \\ edit@eng.unideb.hu
}

Abstract. Business organisations constantly strive to improve their processes, both internal and external. Within the supply chain of a product, different strategies can be applied. This paper aims to answer the basic questions like what is the core of lean and agile SCM strategies, what are the differences of the two models, and how can they be combined. This paper examines further, which of these SCM models and what elements of them can be applied for wood pellet supply chains, also examining the possibility of their combination. The result of these examinations is, that even though fuel pellets can be considered as simple commodity and not a very innovative product, diversity in input characteristics, optimization of fuel pellet technology process variables and changes in output market qualities and quantities need sometimes agile, flexible answer from pellet fuel SCM. The basically lean character of pellet fuel technologies and SCM can further enhanced by implementing agile SCM model elements, as is the increased integration of suppliers into the supply chain.

\section{Introduction}

In the $21^{\text {st }}$ century, new supply chain concepts are introduced beside the traditional supply chain models in order to maintain the competitiveness of enterprises [7]. Nowadays, good Supply Chain Management (SCM) is an important success factor in business. Supply chains consist of the suppliers, suppliers' suppliers, customers and sometimes even costumers' costumers. The outputs of supply chains are value creation out of combinations of utilities of e. g. time, place, product, and information. This article describes what the main characteristics of lean and agile SCM are, what is their difference and how can these be combined. Then, the main question is: what elements of these SCM models can be applied for wood pellet supply chains. 


\section{Lean and Agile Supply Chain Models}

\subsection{Lean Supply Chain}

The first mention in the scientific literature of the lean supply chain model dates back to the early 1980s. The primary purpose of the application of lean SCM is to reduce the losses in the entire supply chain, first, the elimination of non-value-adding processes, then, continual improvement and reengineering of processes. A number of "Lean" tools are available to meet these goals, such as reducing waiting and changeover time, etc. [1][4].

Taking into account the 21 centuries' logistical and SCM trends, manufacturing can be improved to be more economical and flexible with lean SCM. Lean SCM can be mainly used in the manufacturing of products with relatively long lifetime (longer than one or two years). The part-takers of the chain are working in a network organizational form [4].

\subsection{Agile Supply Chain}

The following, younger, main new SCM concept is called "agile" SCM, which is increasingly used by more and more industries. Agility ("Quickness", "Flexibility") refers to the relationship between the manufacturing company and the customer market, that is, how can the company's SCM flexibly respond to the changes of customer demands. The increased competitiveness and profits of the agile supply chain need the capability of the SCM to react more rapidly to market challenges. The manufactured products have to be more and more tailored for the customer needs, they have to become more and more individual. These products have to be manufactured in increasingly smaller batches, with shorter lead times and lower cost than ever [9].

In case of short-cycle (up to 1 year) innovative products, the participants of the agile supply chain work mostly in dynamic collaboration of a "Virtual Organization", which can serve the ability to meet rapidly changing customer demands faster. The Virtual Organization is a collaboration of legally independent businesses for a short-time period, in order to develop and manufacture market products. The Virtual Enterprise is a temporary alliance of the actors in a supply chain, where participants share their skills, main competencies and resources, so as to better respond to new business opportunities [9][8].

\subsection{Differences between Agile and Lean Supply Chain Models}

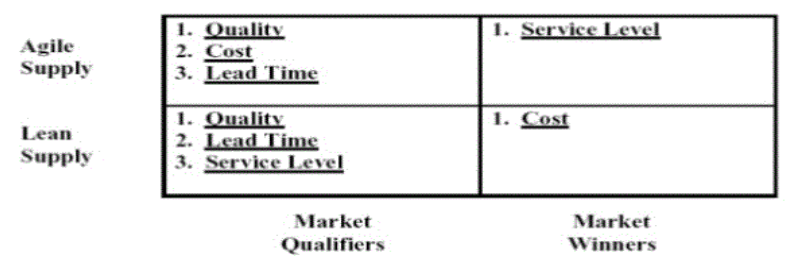

Figure 1. Core differences between lean and agile SCM models [9] 
As the above descriptions suggests, there are differences between the two SCM models. The main differences in terms of market strategy are that for an agile supply chain, service level is in focus, whereas for a lean supply chain, costs are in focus (Figure 1).

\begin{tabular}{|c|c|c|}
\hline denomination & lean supply chain & agile supply chain \\
\hline created & 1980 & 1990 \\
\hline Typical products & Commodities & Fashion goods \\
\hline Market player demand & Predictable & Volatile \\
\hline p. variety & low & high \\
\hline p. life cycle & long & short \\
\hline customer drivers & cost & availability \\
\hline profit margin & low & high \\
\hline dominant costs & physical costs & marketability costs \\
\hline Stock out penalties & long-term contractual & immediate and volatile \\
\hline purchasing policy & buy materials & assign capacity \\
\hline $\begin{array}{l}\text { information } \\
\text { enrichment }\end{array}$ & highly desirable & obligatory \\
\hline forecasting mechanism & algorithmic & consultative \\
\hline logistics focus & Eliminate waste & customers and markets \\
\hline partnerships & long-term sable & fluid clusters \\
\hline key measure & $\begin{array}{l}\text { output measure such as } \\
\text { productivity and cost }\end{array}$ & $\begin{array}{l}\text { measure capabilities and focus on } \\
\text { customer satisfaction }\end{array}$ \\
\hline process focus & $\begin{array}{l}\text { work standardization, conformance } \\
\text { to standards }\end{array}$ & $\begin{array}{l}\text { focus on operator self-management to } \\
\text { maximize autonomy }\end{array}$ \\
\hline logistics planning & stable, fixed period & instantaneous response \\
\hline Manufacturing & Make to forecast & Make to order \\
\hline \multirow{3}{*}{$\begin{array}{l}\text { de-coupling point } \\
\text { approach }\end{array}$} & forecast at generic level & Demand driven \\
\hline & economic batch quantities & localised configuration \\
\hline & maximise efficiencies & maximise effectiveness \\
\hline \multirow[t]{3}{*}{ Product characteristics } & Functional product & innovative product \\
\hline & low variety & high variety \\
\hline & low margin & high margin \\
\hline
\end{tabular}

Table 1. Differences between Lean and Agile SCM

(Source: own compilation based on [9] and [5]) 
A more detailed list of differences is contained in Table 1, covering aspects of typical product type (conventional commodities or innovative products), what type of demand do market players face (predictable or volatile), or what are the main customer drivers.

\subsection{Leagile Supply Chain}

Business corporations strive to improve their processes, both internal and external, using various strategies and tools, lean as well as agile. When comparing data from 216 Australian manufacturing companies, researcher have found clear difference of improvement focus of Make-to-Order (MTO) vs. Make-to-Stock (MTS) firms [12]. In short, the main focus of MTO firms is supplier integration, thereby improving supply chain responsiveness and flexibility, whereas MTS firm focus on lean practices and supplier rationalisation, decreasing the cost level of processes and products.

An important factor to differentiate MTS and MTO type companies and supply chains is the Customer Order Decoupling Point (CODP). "The CODP is the point in the material flow where the product is tied to a specific customer order; the basic choices being make-to-stock, assemble to-order, make-to-order, and engineer-to-order" [11]. In the practice of SCM, the CODP reflects that stock point, from where a customer order process begins. Figure 2 shows the possibilities for the place of CODP within the material flow and the related SCM strategies.

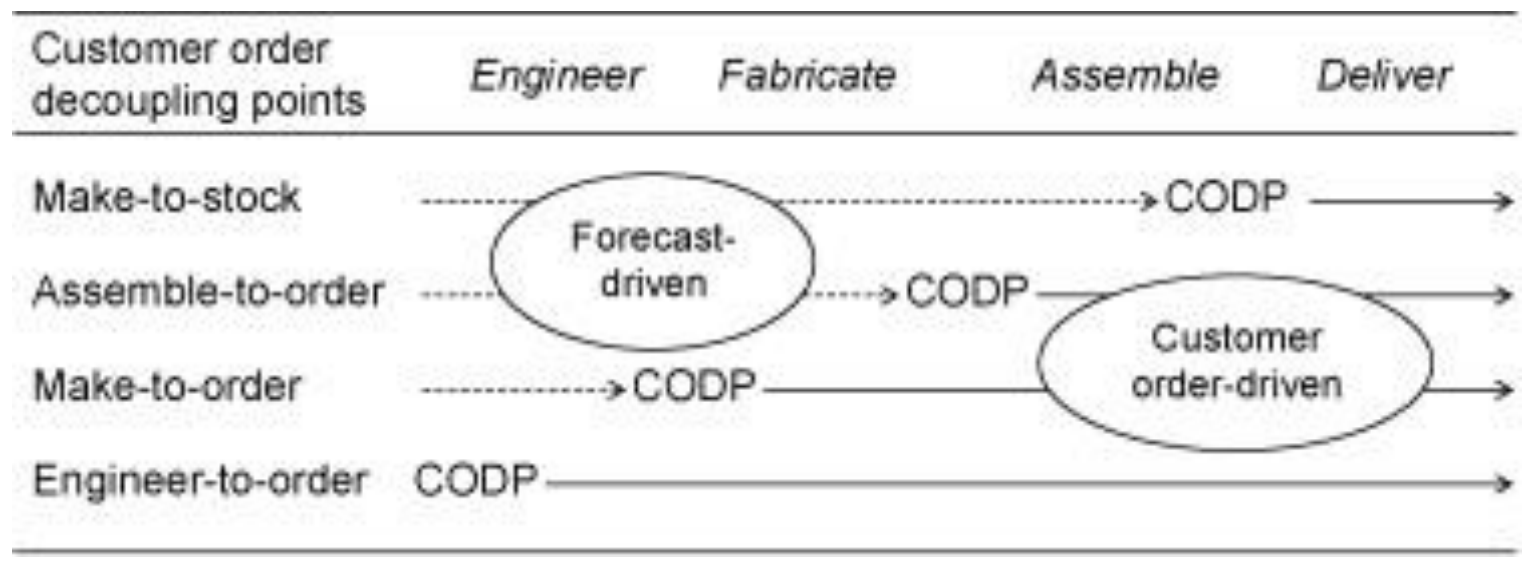

Figure 2. Different customer order decoupling points

(Source: [11])

The point where the actors of the SCM decouple customer order information from the material flow is a differentiating factor for the strategy to be used upstream and downstream in the supply chain. According the location of a specific company within the supply chain, the CODP can be found inside its manufacturing operations or it can be found at the level of suppliers (first tier or even further upstream in the supply chain), or downstream in the SC, at a finished goods inventory, maybe at a seller's seller's warehouse. According to SCM literature [11], strategies to be applied to operations upstream are significantly different than those downstream, basically due to the fact that the processes of the upstream material flow are forecast-driven, while companies involved in the downstream part of the SCM can act on real customer orders. 
The hybrid supply chain (Leagile Supply Chain) is a combination of the "lean" and "agile" SCM models, which combines the advantages of "lean" and "agile" paradigms. This "leagile" SCM strategy is typically used in the case of the production of "assembled to order" products (Figure 1), where customer demand forecasts are relatively accurate, and, by using innovative components, product uniqueness and quality can increase. The strategy enables the implementation of a broad portfolio of customized finished products. This SCM model uses "Lean" tools during production, and this SCM makes use of the advantages of the strategic co-operation of companies in order to follow the rapidly changing demands of customers [10].

\section{Fuel Pellet Technologies and Supply Chains}

Although pellets are „functional” products, not „innovative”, this paper argues that Pellet Fuel Technologies and Pellet Supply Chains do possess the variability that needs „agile”, flexible answers from Pellet Fuel Supply Chain Management.

\subsection{Variations in Fuel Pellet Production Technologies}

In order to examine SCM characteristics, the first question sounds: what is the product in question?

Fuel pellets are made of dried woody or non-woody biomass via pelletizing with a pellet press. These pellets have then a cylindrical shape and small dimensions of $1-5 \mathrm{~cm}$ in length and about $0.5-1 \mathrm{~cm}$ diameter. Their main feature is their heat value, which is around $15 \mathrm{MJ} / \mathrm{kg}$, depending on material and moisture content. Their typical use is heating in residential buildings or municipal institutions, or in processing industry facilities.

Pellets are typical commodity products. However, pellet production and its logistics do have some variety that must be addressed. For the logistics, the main characteristics are pellet density and pellet durability. The higher the density of the pellets, the more efficient their transport and storage. Similarly, the higher the durability of the pellets, the better their quality at the end of the transport and product material handling throughout the supply chain operations.

Pellet fuel production technologies have to cope with the changes in the price, quality and quantity needed on pellet markets. On the other side, inputs for pellet technology operations is dependent on woody and non-woody biomass availability - price, quality and quantity. The differences in the mixture proportion of raw material, as well as moisture content and the chosen pressure for compaction for three raw materials, namely, sawdust, wheat straw and rapeseed straw [18] are shown on Figure 3 and Figure 4. 
a

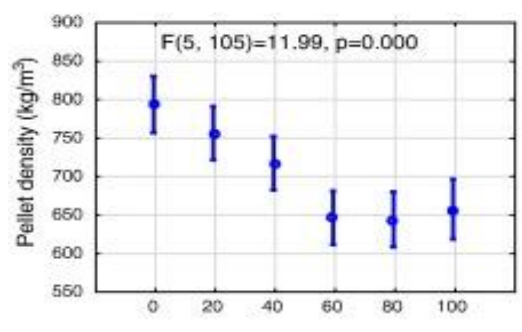

Percentage of wheat straw $(\%)$

d

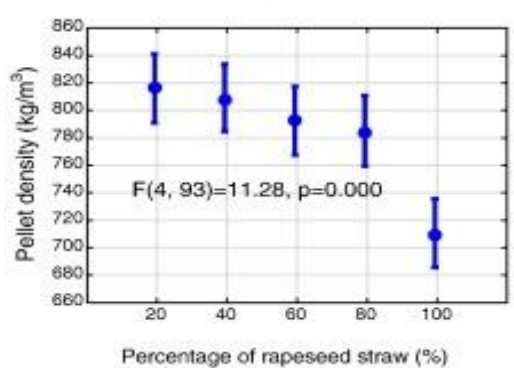

b

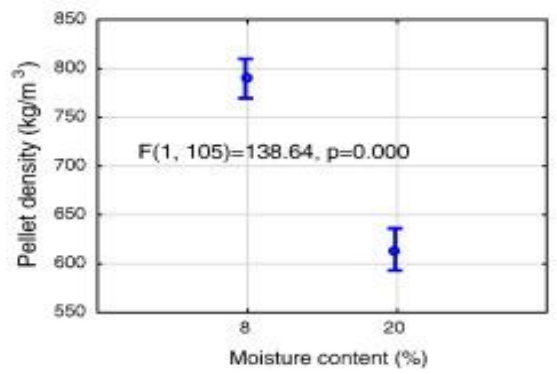

e

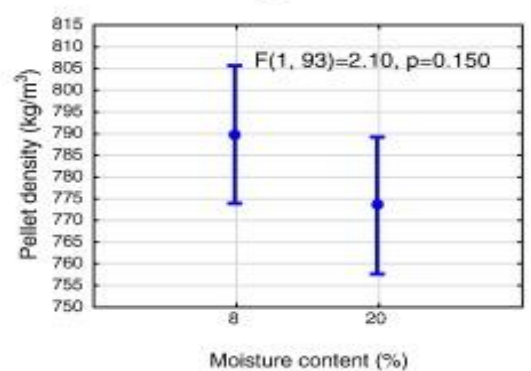

C

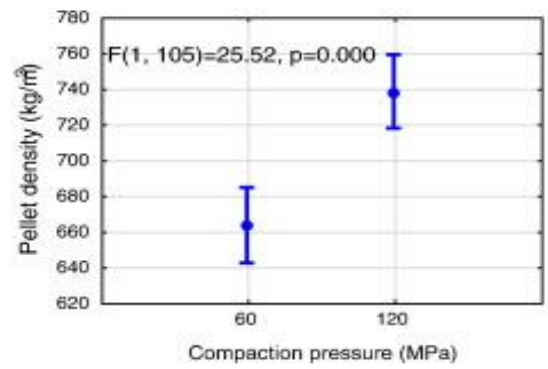

$f$

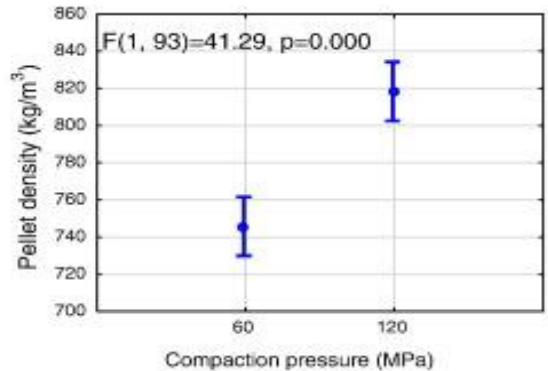

Figure 3. Mean values of pellets density for sawdust-wheat straw mixtures a) b) c) and sawdust-rapeseed straw mixtures d) e) f)

(Source: [15])

a

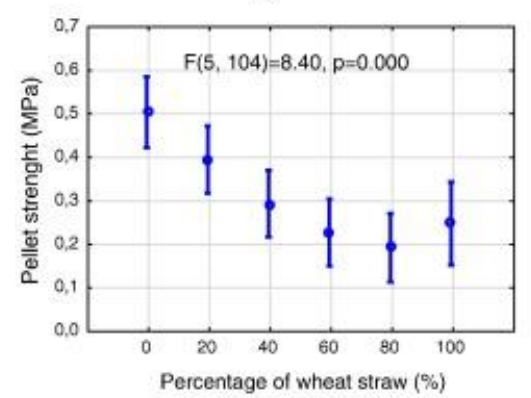

d

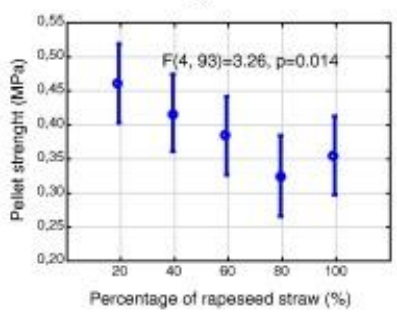

\section{b}

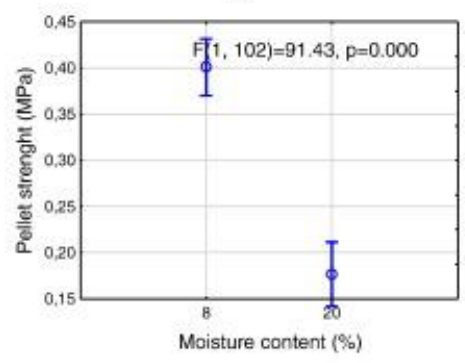

e

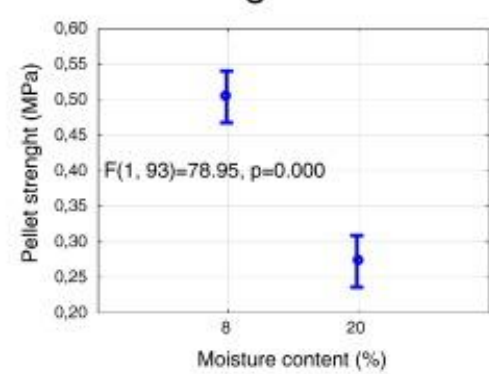

C
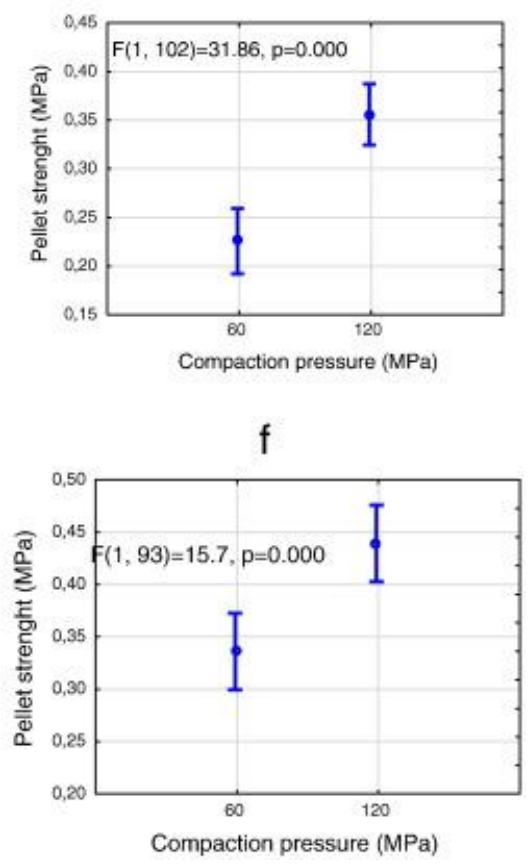

Figure 4. Mean values of strength of the pellets $\sigma_{B}$ as dependent on proportion of straw, moisture content and compaction pressure for sawdust-wheat straw mixtures a) b) c) and sawdust-rapeseed straw mixtures d) e) f)

(Source: [15]) 


\subsection{Fuel Pellet Markets}

As regards the complexity of pellet SCM, the simplest logistical chains are quite easy to handle. This refers to the intralogistics of non-market quality pellets, which can serve e.g. as fuel for drying in the production process. A pellet plant can sell its production entirely locally, in case the scale of the technology, i.e., the capacity of the factory is small enough compared the fuel needs of local residents and organisations. However, if there is enough supply of raw material and sufficient demand for economic production and distribution, supply chains become larger and regional. An example for regional chains and networks is the development of the wood pellet business in North-West Russian regions [14]. The growing number of pellet production factories indicated an enlarging trade with buyers in European (especially Baltic) countries [13]. Geographical and statistical data of this supply network development are shown on Figure 5.

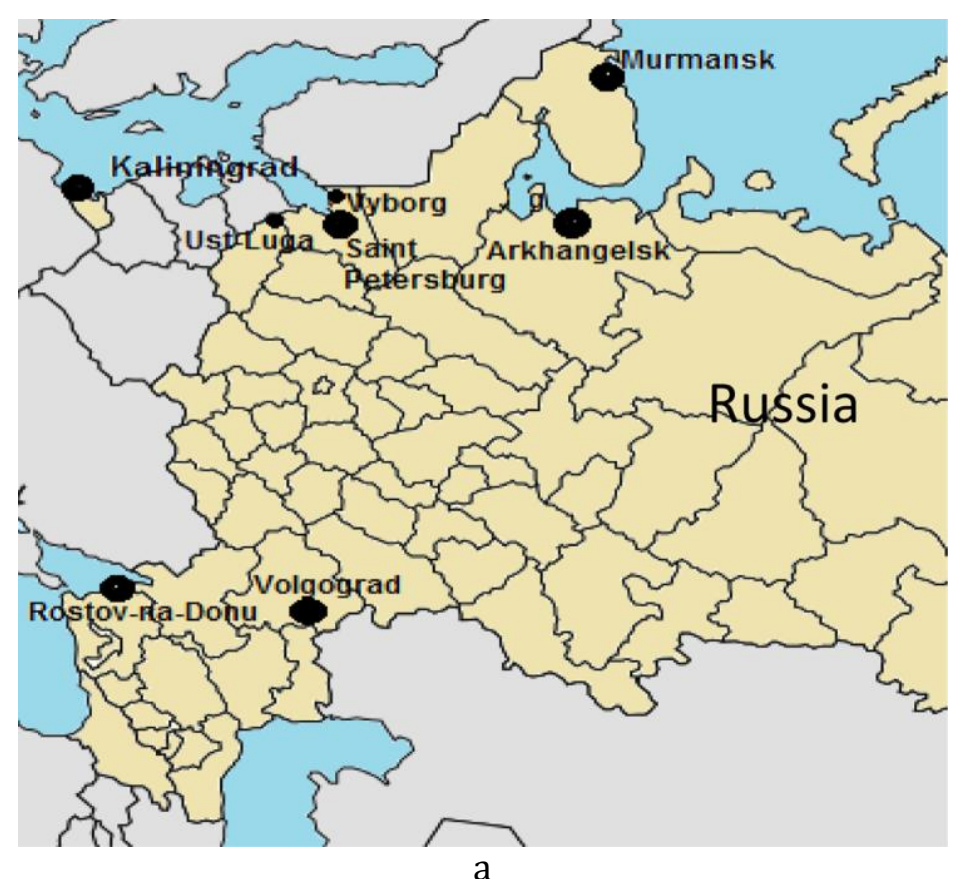

Figure 5. Map of the main seaports in western Russia a), first pellet plants in the Leningrad region, 2004 b) and number of pellet plants in Russia during 2001-2009

(Source: [13] $(b, c),[14](a))$

Sea transport allows for not only regional, but global, intercontinental trade as well. The modelling approach illustrated on Figure 1 serves optimisation of fuel pellet supply chains from North-East Canada to Rotterdam, Europe, via the Atlantic sea [2].

\subsection{Pellet Fuel Supply Chains}

Woody and non-woody biomass based fuel pellets have the basic supply chain configuration of physical products, with input suppliers, processing facilities and market distributors. Boukherroub et 
al. [2] have investigated an approach of a wood pellet supply chain developing model (SC) which selects among several sources of biomass feedstock. The base for the model was that a pellet factory can use biomass harvested in the forest and sawmill residues in the mix of feedstock, with different locations for each input source and pellet processing facility, and then the pellets can be shipped to different markets (Figure 6).

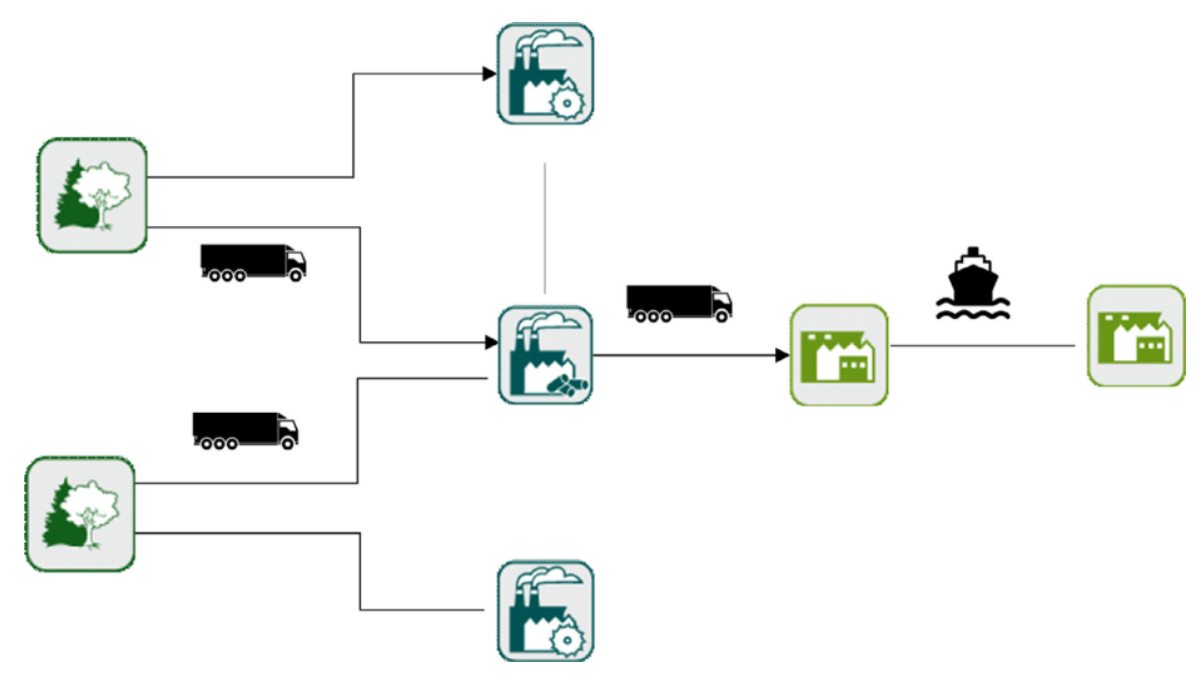

Figure 6. Integrated Wood Pellet Supply Chain

(Source: [2])

The cited approach [2], calculating on pellet market demand assumptions, has led to overall optimization of a Canada-based pellet supply chain (Figure 7). The five steps of the building up their model were (1) projected demands on potential markets, (2) variables of feedstock types, locations, and available quantities, (3) options of raw material and final product transportation, and plant location, with (4) cost estimations, and (5) optimization. The approach, applied to a real case study in Eastern Canada, have resulted in three different capacities and profitability, depending on feedstock (solely biomass harvested in the forest or sawmill residues as well) and wood pellet selling price. 


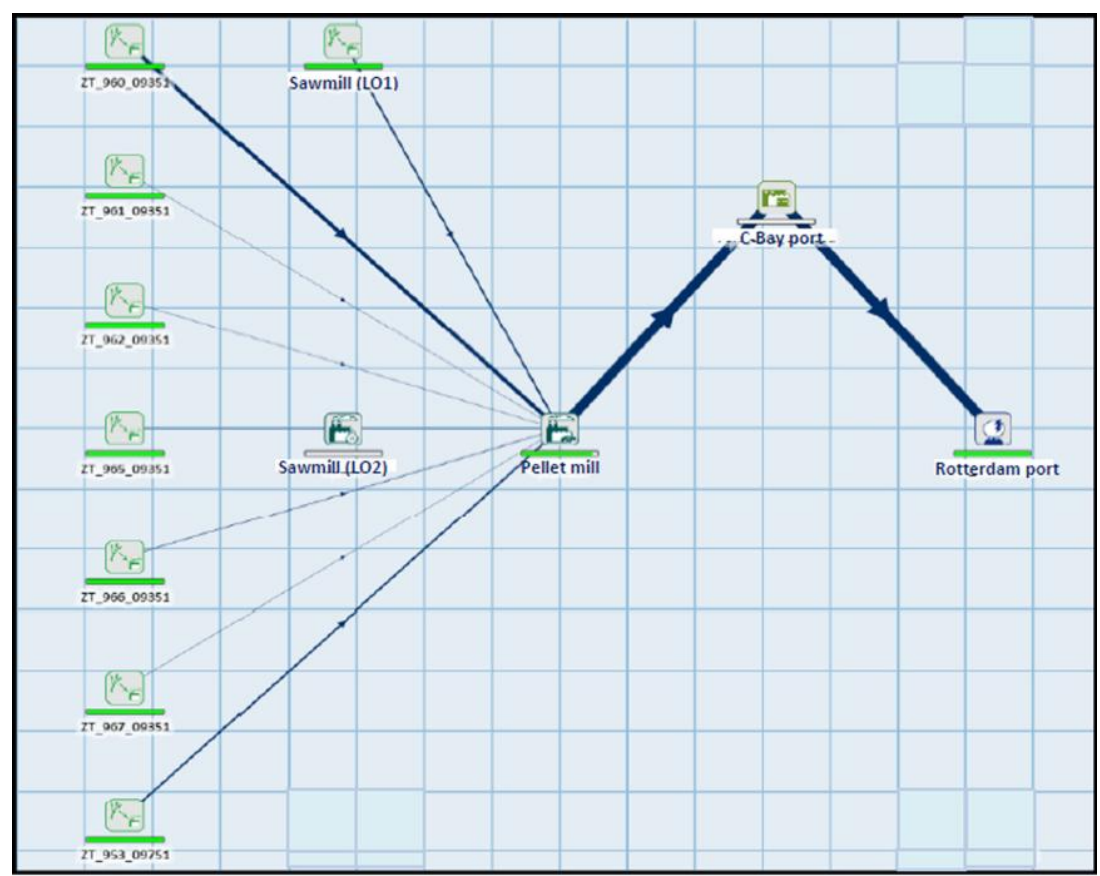

Figure 7. Pellet Supply Chain Calculations - from Canada to Rotterdam

(Source: [2])

Based on the above considerations, the conclusion can be drawn: although pellets are "functional" products, not „innovative”, Pellet Fuel Technologies and Pellet Supply Chains do possess the variability that needs „agile”, flexible answers from Pellet Fuel Supply Chain Management.

\section{Lean and Agile Supply Chain Models for Pellet Fuel Technologies}

\subsection{Lean}

In terms of the above definition of what a lean supply chain is, pellet fuel supply chains are lean by their nature: they aim to eliminate forestry and wood industry waste, at the same time creating value via the product called fuel pellet. Since operation and logistic costs on factory and supply chain level are very important factors in their business processes, pellet fuel supply chains - if properly designed and operated - are lean in their supply chain management as well. This type of SCM is investigated by many publications, according to [6]

\subsection{Agile}

In line with the above detailed characteristics of agility, many definitions and understandings exist as of what agility is. In a 2012 survey, 117 supply chain executives gave a definition of agility [3]. Their answers were grouped in four clusters. In terms of product market demand volatility, the first approach might be the "flexibility to make and deliver whatever is ordered". The simplest term for agility is "shorter supply cycles", which focusing on the time aspect of agility. A more comprehensive answer for what agility is covers input and product markets: "Ability to adapt to variations in demand 
and supply". The majority of the experts formulated the most mature answer: Agility is "the design of the supply chain to have the same cost, quality and customer service given the level of demand and supply volatility."[3]

Although little research has been carried out on the agility of pellet fuel supply chains, some hints can be formulated, based on the above definition of agility and the fundamental elements of a pellet supply chain. Agility in this case means flexible and rapid answers for differences and changes in specifications and types of wood pellets, as regards individual buyers or specific market regions demanding fuel pellets. Differences and changes of supply markets, feedstock availability (type, quality, price, and location) need flexible and rapid answers as well. Agility is needed in pellet fuel production technology operations (differences in processing techniques and scheduling), as well as in the (inbound and outbound) logistics throughout the supply chain, optimizing methods and locations during purchasing and distribution.

\subsection{Leagile}

As we could see in the previous considerations of lean and agile supply chains, there is a difference between firms implementing make-to-order vs. make-to-stock supply chain models. The study highlighting [12] that MTS firms achieve lean practices in many cases through supplier rationalisation, contrasts this to the model of MTO firms stress supplier integration, thereby enabling information flow and decision making throughout the supply chain. This can ensure a more timely answer to pellet market demand changes. A higher level of supplier integration can ensure better supply market data as well, also enhancing the ability of the supply chain to rapidly adapt to the changes. Nevertheless, further improvement of the inner processes of the SC participants, as well as improved logistic operations, are also needed - being lean in their character. This lean improvement of processes and the agile supply chain information integration can then represent a new and better supply chain model, the "leagile" fuel pellet supply chain.

\section{Conclusion}

According to supply chain management literature, lean and agile supply chain models have to be distinguished, according to their features. Lean SCM models concentrate on eliminating material and processual wastes, to make the processes smoother and cheaper, basically in case of forecast-based traditional commodity production. Agile SCM models concentrate on market changes, mostly in case of innovative products, letting customer orders penetrate upstream the supply chain. According to the position of the Customer Order Decoupling Point within the supply chain, different production and SCM models can be observed. Two main SCM concepts are the Make-to-Order (MTO) and Make-toStock (MTS) approach. If MTO versus MTS differences are not accounted for, then the wrong conclusions can be drawn; however, with proper application, these can be beneficially combined. Although based on different market needs, lean and agile SCM models are not inherently adverse - a "Leagile" SCM is theoretically possible. A practical implementation can be to apply the agility- 
enhancing element of supplier integration of MTO SCM model even to the basically supplierrationalizing MTS model of a lean SCM.

Although pellets are „functional” products, not „innovative”, Pellet Fuel Technologies and Pellet Supply Chains do possess the variability that needs „agile”, flexible answers from Pellet Fuel Supply Chain Management. To answer the challenges of input and output market variability, and to optimize fuel pellet technology process variables, MTO type SCM elements can be integrated e.g. by establishing a closer cooperation of both input suppliers and pellet producers and distributors. This should not weaken the basically „lean” character of Pellet SCMs, rather upgrade them to a „leagile” supply chain management model.

\section{References}

[1] Agarwal, A., Shankar, R., Tiwari, M. K. (2007). Modeling agility of supply chain. Industrial Marketing Management, Vol.36 pp443-457.

[2] Boukherroub, T., LeBel, L., Lemieux, S. (2016). An integrated wood pellet supply chain development: Selecting among feedstock sources and a range of operating scales. Applied Energy. Article in Press, pp1-16.

[3] Cecere, L. (2012). S\&OP planning improves supply chain agility. Supply Chain Insights LLC Research Reports May 2012, pp1-16.

[4] Christopher, M., Towill, D.R. (2000). Supply chain migration from lean and functional to agile and customised. International Journal of Supply Chain Management, Vol.5 No.4 pp206-213.

[5] Gilaninia, S., Taleghani, M., Mousavian, S.J., Kouchaki Tajani, T., Ghoreishi, S.M., Shahidi, S.F., Zadbagher Seighalani, F. (2011). Comparative study of lean and agile supply chain management along with the optimal model presentation of agile supply chain management. Journal of Business and Management 1, pp46-56.

[6] Hughes, N.M., Shahi, C., Pulkki, R., 2014. A Review of the Wood Pellet Value Chain, Modern Value/Supply Chain Management Approaches, and Value/Supply Chain Models. Journal of Renewable Energy 2014, e654158.

[7] Kovács 2016 (LIM) Kovács, György, (2016). A XXI. századi logisztikai tendenciák és kihívások. Presented at the LIM 2016 - Logisztika-Informatika-Menedzsment Nemzetközi Konferencia, BGE Gazdálkodási Kar, Zalaegerszeg, pp. 1-14.

[8] Lin, C.T., Chiu, H., Chu, P.Y. (2006). Agility index in the supply chain. International Journal of Production Economics, Vol.100 No.2 pp285-299.

[9] Mason-Jones, R., Naylor, J.B. and Towill, D.R. (2000). Engineering the leagile supply chain. International Journal of Agile Management Systems, pp 54-61. 
[10] Naylor, J.B., Naim, M.M., Berry, D. (1999). Leagility: integrating the lean and agile manufacturing paradigms in the total supply chain. International Journal of Production Economics, Vol.62, pp107-118.

[11] Olhager, J., 2010. The role of the customer order decoupling point in production and supply chain management. Computers in Industry, Trends and Challenges in Production and Supply Chain Management 61, pp863-868.

[12] Olhager, J., Prajogo, D.I., 2012. The impact of manufacturing and supply chain improvement initiatives: A survey comparing make-to-order and make-to-stock firms. Omega 40, pp159165.

[13] Proskurina, S., Heinimö, J., Mikkilä, M., Vakkilainen, E., 2015. The wood pellet business in Russia with the role of North-West Russian regions: Present trends and future challenges. Renewable and Sustainable Energy Reviews 51, pp730-740.

[14] Proskurina, S., Rimppi, H., Heinimö, J., Hansson, J., Orlov, A., Raghu, K., Vakkilainen, E., 2016. Logistical, economic, environmental and regulatory conditions for future wood pellet transportation by sea to Europe: The case of Northwest Russian seaports. Renewable and Sustainable Energy Reviews 56, pp38-50.

[15] Stasiak, M., Molenda, M., Bańda, M., Wiącek, J., Parafiniuk, P., Gondek, E., 2017. Mechanical and combustion properties of sawdust-Straw pellets blended in different proportions. Fuel Processing Technology 156, pp366-375. 